\title{
Paisaje, nación y representación del sujeto popular. Visiones de un Chile imaginado'
}

\section{Landscape, Nation and Likeness of the Peasant. Views of an Imaginative Chile}

\author{
Sebastián Schoennenbeck Grohnert \\ Pontificia Universidad Católica, Chile \\ sschoenn@uc.cl
}

\section{Resumen:}

Al suponer el paisaje como un modo de representar e imaginar la nación, este trabajo analiza la pintura de Alejandro Ciccarelli Vista de Santiago desde Peñalolén y algunas descripciones paisajísticas presentes en los relatos chilenos Durante la reconquista (Alberto Blest Gana), Días de Campo (Federico Gana) y Zurzulita (Mariano Latorre) como construcciones que tienen a invisibilizar su carácter histórico y, por ende, a naturalizar ideológicamente los imaginarios nacionales. Los paisajes analizados han sido históricamente contextualizados en diferentes escenificaciones del tiempo nacional (B. Subercaseaux) en la medida que eliden o presentan parcialmente al sujeto popular.

Palabras clave: paisaje, sujeto, nación.

\begin{abstract}
:
When assuming the landscape as a way of representing and imagining the nation, this work analyzes the painting of Alexander Ciccarelli Vista de Santiago desde Peñalolén and some present landscaping descriptions in the Chilean stories Durante la Reconquista (Alberto Blest Gana), Días de campo (Federico Desire) and Zurzulita (Mariano Latorre) as constructions that faints its historical character and, therefore ideologically naturalizes the national imaginary. The landscapes analyzed herein have been historically placed in different time scenes of the nation (B. Subercaseaux) to the extend that they leave out or partially present the popular subject.
\end{abstract}

Keywords: Landscape, Subject, Nation.

1 Este artículo es resultado del Proyecto de Iniciación fondecyt N 1111004 “El paisaje en la literatura y pintura chilena: representación, ideología y nación". 
El paisaje es un género en el que podemos visualizar discursos vinculados a la construcción de imaginarios nacionales. Al respecto, Chile y la formación histórica de su institucionalidad republicana es un caso particular en comparación con las otras jóvenes repúblicas latinoamericanas del siglo $x \mathrm{XX}^{2}$. Por lo tanto, tal vez vale la pena revisitar algunos paisajes pictóricos y literarios. Considerando las relaciones entre paisaje y país, podemos afirmar, a modo de premisa, que el paisaje, en cuanto imagen construida culturalmente, está sujeto a un proceso ideológico de naturalización gracias al cual la nación será identificada con un espacio natural que, dada su permanencia en el tiempo, trasciende la transitoriedad histórica de los ciudadanos, presentándose como esencia, naturaleza y origen de la nación. En otras palabras, es posible afirmar que el paisaje aparenta algo que no es y es a través de dicha apariencia como coopera discursivamente en la formación de una identidad nacional que también ha pretendido invisibilizar su carácter histórico.

La naturalización del paisaje, mecanismo ideológico con el cual los imaginarios nacionales son construidos, puede ser explicada con cierta comprensión de lo clásico, tal como Alfredo Jocelyn-Holt lo expone en su análisis sobre Histórica Relación del Reino de Chile del sacerdote jesuita Alonso de Ovalle. Para el historiador, lo clásico puede ser identificado con aquello que no cambia:

Lo clásico supone un desentrañamiento de ciertas constantes si es que no una lógica compartida que estaría y nos remontaría a la naturaleza misma... Esto, porque cuando se asume una perspectiva clásica o clasicista se tiende a sintonizar con lo mismo, con lo constante. De ahí la uniformidad común, valga la redundancia, en todas las visiones "clasicizantes" y la insistencia en el paisaje... En otras palabras, lo que apreciamos como clásico en sus obras no sería más que la constatación de persistencias que estarían presentes en la misma naturaleza (43-4).

Lo anterior explica la usual identificación del paisaje como la representación de espacios naturales (la cordillera, el campo, la campiña, el mar, etc.), aunque, en estricto rigor, según Berque ${ }^{3}$, podemos hablar también, por ejemplo, de paisaje urbano o industrial.

La aparente permanencia del paisaje que lo vuelve una esencia falaz esconde, sin embargo, una serie de transformaciones históricas. Entre ellas, cabe destacar el tipo de flora (endémica o introducida) que componen dicho paraje, el nivel de intervención humana en el espacio y la presencia del sujeto popular en el entorno rural, variante que será privilegiada en este estudio.

2 Según Roberto Amigo, en el catálogo de la exposición "Territorios de Estado. Paisaje y cartografía. Chile, siglo XIX” llevada a cabo en el Museo Nacional de Bellas Artes de Santiago (2009), "El arte chileno del siglo XIX sobresale en la región por el establecimiento de la primera Academia de Bellas Artes fundada en las jóvenes repúblicas. Esta temprana institucionalidad potenció la discusión artística y la implantación de géneros pictóricos, entre ellos la pintura de paisajes de escasa presencia en otros países sudamericanos" (s/p)..

3 Ver Berque, Agustín. El pensamiento paisajero. Madrid: Biblioteca Nueva, 2009. 


\section{Paisaje, ocio y negocio}

Una posible explicación sobre la representación o elisión del sujeto campesino en el paisaje ha sido expuesta por Raymond Williams. En su obra El campo y la ciudad (1973), el pensador de la Escuela de Birmingham describe la suspensión del sujeto trabajador como la retórica a través de la cual se construye lo rural como un paraíso:

Con todo, esa supresión mágica de la maldición del trabajo se logra mediante la simple eliminación de la existencia de los trabajadores. Los hombres y mujeres reales que crían animales y los conducen a la casa, los matan y los preparan para la cena; que cazan faisanes y perdices y capturan peces; quienes plantan, abonan, podan y cosechan los árboles frutales, no están presentes. Un orden natural se ocupa de hacerles el trabajo (60).

Desde la mirada de la elite social, el paisaje es el reflejo de un espacio que solo se contempla. Por ende, solo el sujeto que puede cultivar el ocio transforma el campo en paisaje. Beatriz Sarlo, en el prólogo a la edición española de la obra de Williams recientemente mencionada, afirma lo siguiente:

el paisaje, tanto en su dimensión material como en su referencia literaria, es la producción de un tipo particular de observador, sustraído del mundo del trabajo. El paisaje es un punto de vista, antes que una construcción estética. Es más: para que la intervención estética paisajística tenga lugar, es preciso su articulación con un punto de vista que anula el trabajo y despersonaliza la fuerza de trabajo. El campo nunca es paisaje antes de la llegada de un observador ocioso que puede permitirse una distancia en relación con la naturaleza (19).

A partir de su lectura de Los trabajos y los días de Hesiodo, Agustín Berque afirma que históricamente la división social del trabajo ha generado una compleja gama de experiencias tales como el trabajo y el descanso que permite la contemplación de la naturaleza, el negocio y el ocio. A través de tales oposiciones, las elites cultivadas llevaron a cabo lo que el autor denomina la forclusión del trabajo de la tierra, es decir, el ciudadano, que cultivaba no la tierra sino la palabra y las artes, deja fuera de su campo de visión la faena agrícola que realizaría el sujeto trabajador, instalando así el mito de la Edad de Oro, época en la que el trabajo no era necesario, ya que, contradictoriamente, el suelo cultivado producía por sí mismo o naturalmente una buena cosecha:

Hacer trabajar a los demás fue esencialmente y durante milenios hacerles trabajar la tierra. De ahí surgieron las ciudades y fue, por tanto, a partir de las ciudades desde donde se pudo dirigir una mirada desinteresada -surgida del frui, no del uti- al entorno; se suscitaron de ese modo representaciones de "la naturaleza" que permitieran hacer de ella un objeto de conocimiento (de esto nace la ciencia) o de pura contemplación (de esto nace el pensamiento del paisaje) (Berque 41). 


\section{Paisaje y nación}

Al develar las vinculaciones etimológicas e históricas entre los conceptos de país y paisaje, Javier Maderuelo indica el término latino pagus (aldea, distrito y campo) y la importancia de su ablativo, pago, para la lengua española:

Pago, con su forma latina inalterada, es una palabra que aparece en documentos españoles desde el año 1100 y que aún perdura para referirse a una tierra o heredad.... Pero, con el paso del tiempo, el término pago, como expresión de la idea de lugar, fue dejando paso a la palabra país, que expresa las ideas de región, provincia o territorio y que, junto a nación, son las acepciones que actualmente posee el término país (El paisaje 25).

En suma, la palabra castellana pago indica una superficie de tierra cultivable que conlleva el trabajo del labriego y el valor económico con el cual se compra y se paga otro bien. Para Francisco Calvo Serraller, el término tiene fuertes connotaciones utilitarias. Por ende, el pago se transformará en país y en paisaje cuando deje ser una tierra rentable y así el sujeto pueda contemplar desinteresadamente la belleza del lugar:

Hace falta que el hombre se libere de esa carga onerosa y pueda mirar a su alrededor sin la preocupación de que una tormenta o la sequía arruinen su economía para que pueda realmente recrearse en fenómenos como la lluvia, el crepúsculo, la aurora o la variedad de luces y tonalidades que dejan las estaciones a su paso (11-2).

Maderuelo complementará las afirmaciones de Calvo Serraller al decir que la transformación del pago en paisaje y país tiene lugar cuando el sujeto toma conciencia de las características peculiares de la tierra que habita y originalmente trabajaba, estableciendo diferencias con otros lugares. Solo cuando el sujeto deja de ser una parte indisoluble del lugar, tendrá cabida el paisaje. De este modo, en un contexto medieval, el paisaje es una imposibilidad, ya que el hombre rústico era dependiente de la tierra según el sistema de propiedad feudal. El paisaje, en cambio, surgirá en la medida que el sujeto observante, liberado del trabajo agrícola, goce de movimiento, desplazamiento y, por lo tanto, cierto grado de independencia ontológica con respecto al paraje observado.

Para Claudio Minca, la asociación nación/paisaje guarda relación con la pugna entre geografía pura y geografía del estado, es decir, un conflicto entre el conocimiento científico y una teoría política del espacio. Esta pugna será resuelta por la burguesía que, en el momento de su consolidación política, establecerá un compromiso entre poder y saber: "El paisaje es uno de los resultados de este formidable y perjudicial compromiso entre razón científica y razón de estado, entre la nueva estructura de la cultura burguesa y las exigencias paralelas de legitimación de su toma de poder, un compromiso que se traducirá en la más extraordinaria invención geográfica de la modernidad: el estado nación" (215). Minca adjudica a Alexander Humboldt la mutación del paisaje como concepto estético a concepto científico. Así, el carácter estético de la cultura burguesa y su saber artístico se transformaron en ciencia de la naturaleza, fortaleciéndose el compromiso entre el saber y el poder. 


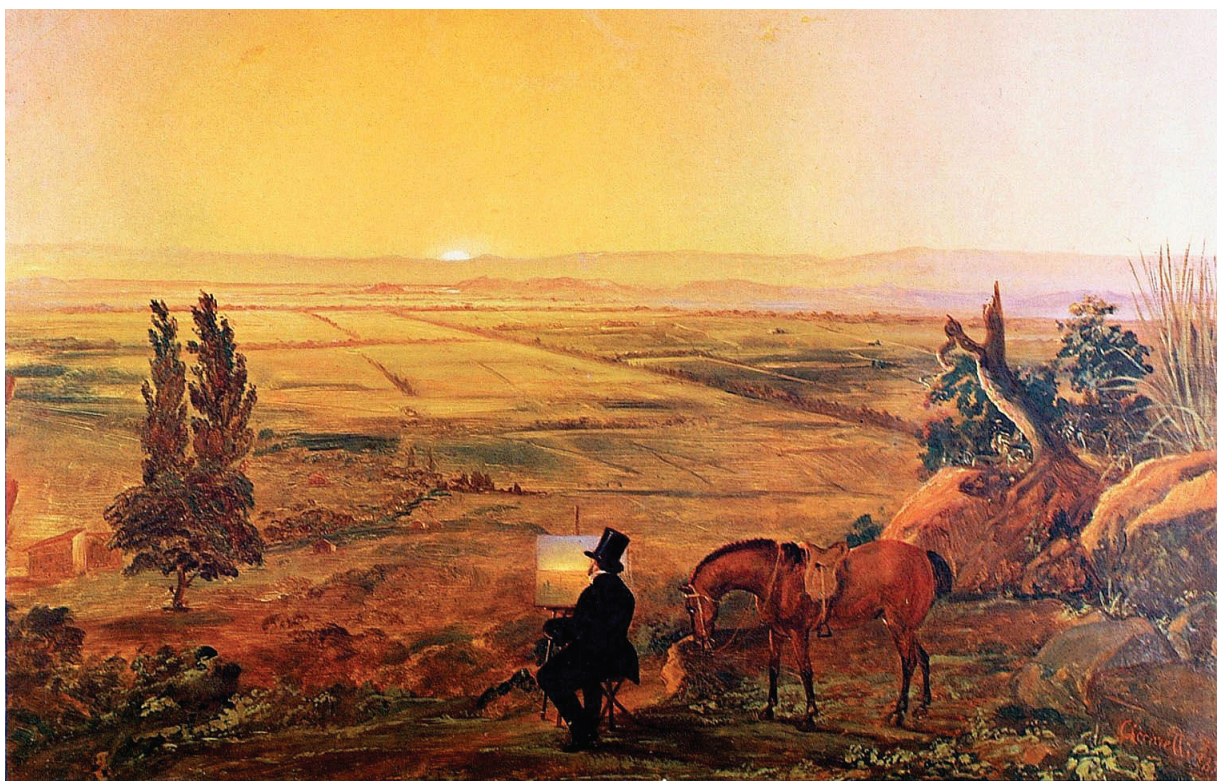

Figura 1. Alejandro Ciccarelli. Vista de Santiago desde Peñalolén (1861). Fuente: Portal del arte. Sitio web.

\section{Tres paisajes}

Con el objetivo de develar el carácter artificial de un paisaje naturalizado, esta reflexión propone establecer tres modalidades en las que este género se pronuncia acerca de la nación ya sea por medio de la exclusión o inclusión del sujeto campesino.

La primera modulación del paisaje corresponde a la segunda mitad del siglo XIX y puede reconocerse en la pintura titulada Vista de Santiago desde Peñalolén (1861; ver Figura 1) del italiano Alejandro Ciccarelli (1811-1879) así como en algunos pasajes de la novela Durante la reconquista (1897) de Alberto Blest Gana (1830-1920). En ambas obras, se presentan espacios "naturales" vistos desde la mirada burguesa que elide la presencia del sujeto popular. Durante la segunda mitad del siglo XIX, el paisaje estará mediado socialmente por la mirada del sujeto urbano y de elite. Se trata de una representación oligárquica presente tanto en la pintura como en la literatura:

En la literatura del siglo XIX, el país equivale, en gran medida, al "vecindario decente", a la elite o a quienes aspiraban a serlo. En la obra de Blest-Gana, el más importante novelista del siglo XIX, el campo es un lugar de recreo para santiaguinos en vacaciones. En algunas novelas costumbristas, como La montaña (1897) de Carlos Silva Vildósola, el campo aparece con signos de pintoresquismo, desde una mirada citadina. Sólo después de 1900, el campo adquiere vitalidad literaria por sí mismo, como naturaleza y conformador de vida, aislado de la ciudad (Subercaseaux, "Literatura, Nación y Nacionalismo" 6). 
Una segunda modulación del paisaje será identificada en los cuentos de Federico Gana reunidos por Pedro Prado bajo el título Días de campo (1916). Los paisajes privilegiados en estos relatos son los parajes del valle central de Chile, sus campos y potreros que parecen sistematizados bajo el orden de la hacienda. La mirada que estos paisajes suponen es aristocrática, panorámica y totalizadora: el personaje narrador de los cuentos de Federico Gana, patrón y dueño del fundo del valle central, observa los espacios descritos montado en el caballo, es decir, goza de una altura que le permite una perspectiva privilegiada y, por ende, un campo de visión mayor en comparación con aquel que mira estando solo de pie. Los paisajes de Federico Gana, a diferencia de los incluidos en la etapa anterior, incluyen al sujeto popular y trabajador. Sin embargo, este carece de fuerza dramática, ya que su presencia no supone un conflicto con el personaje narrador. Encerrado en su propia melancolía y pathos, el patrón observa al campesino siempre desde la distancia indolente, jamás inmiscuyéndose emocionalmente en su representación. En este sentido, el paisaje de Federico Gana está íntimamente familiarizado con la escena de costumbres: el campesino es una parte esencial del espacio. Lo que se pretende demostrar es que el sujeto popular está representado desde una distancia social con respecto al observador.

Finalmente, proponemos una tercera modulación del paisaje cuyo representante es Mariano Latorre y su novela Zurzulita (1920). Dentro de lo que se ha venido denominando criollismo ${ }^{4}$, la particularidad del paisaje de Mariano Latorre radica en identificar los valores de la nación más con la misma naturaleza (el canto de los pájaros, el follaje perenne de los árboles de la zona central del territorio nacional, la brillantez de los cerros de la cordillera de la costa al ser iluminados por el débil sol de los finales del invierno) que con el sujeto popular. En efecto, la novela apela a los lectores a identificarse con estas imágenes familiares alta y positivamente valorizadas para así generar un alto nivel de pertenencia a una comunidad tanto lectora como nacional/territorial. Por el contrario, al campesino no se le representa como un portador de valores éticos sobre los cuales se sustentaría una comunidad e identidad nacional, aunque sí como una figura idiosincrásicamente propia y particular del espacio agrario ${ }^{5}$, ya que su carácter estaría, según la novela, determinado por aquel espacio. En este sentido, Zurzulita, novela sintetizadora del criollismo chileno, mantiene una tradición con el naturalismo.

Pese a lo anterior, Mariano Latorre incorpora al sujeto campesino con un mayor dramatismo en comparación con Gana, insertándolo indisolublemente en el paisaje. Lo anterior señala el modo a través del cual la literatura, durante las dos primeras décadas del siglo xx en Chile, comienza a incorporar de manera inédita personajes marginales de la ruralidad, otorgándoles protagonismo. Al mismo tiempo, el valor endémico del paisaje adquiere una enorme relevancia en tanto estrategia de representación de lo nacional. Así,

4 Para una profundización del término criollismo, ver Latcham, Ricardo. "La historia del criollismo". Criollismo. Santiago: Universitaria, 1956.

5 Burgos, Fernando. "Reflexiones sobre el cuento criollista”. Anales de la Literatura Hispanoamericana 27 (1998): 35-58. 
apreciamos un realce del "componente de tradición vernácula, con el objetivo de reinsertar esas particularidades en la narrativa de la nación” (Subercaseaux, "Literatura, Nación y Nacionalismo" 7).

Estas tres modulaciones del paisaje guardan, en cierta medida, un correlato con el modelo histórico que Bernardo Subercaseaux ha planteado en su obra Nación y cultura en América Latina. Diversidad cultural y globalización (2002). Aquí, el autor hablará de escenificaciones del tiempo nacional y del tiempo histórico, permitiendo identificar el tiempo fundacional, el tiempo integrador, el tiempo revolucionario y el globalizado:

Las escenificaciones aludidas se prolongan, sin embargo, más allá de las décadas de plena vigencia, llegando incluso a sobreponerse e interactuar, a veces polémicamente, entre sí. En la primera etapa se trata de construir desde la elite y el Estado una nación de ciudadanos, de educar y de civilizar en el marco de un ideario republicano e ilustrado; en la segunda, sin abandonar este marco, pero ampliándolo, se busca integrar a los nuevos sectores sociales y étnicos, extendiendo los servicios del Estado y reformulando el concepto de nación hacia el mestizaje; en la tercera, se pretende transformar la estructura socioeconómica en beneficio de los trabajadores y de los más pobres, vinculando el concepto de nación al de clase y al de antiimperialismo; y en la cuarta, insertarse en el nuevo escenario de la globalización pero preservando la identidad en un contexto de diversidad cultural, o que requiere, una vez más, reformular el imaginario de la nación (12-3).

El paisaje construido por Ciccarelli y Blest Gana, un espacio cuya representación no contempla la presencia del sujeto popular, podría ser ubicado en el tiempo fundacional en la medida que está mediado por la mirada de elite. El de Federico Gana y el de Mariano Latorre, por el contrario, se reconocerían como voces de la escena de la integración, pese a las diferencias entre sí. En ambos no se supone una cabal representación autónoma del sujeto campesino, sino una integración de este último a un orden social y estético ya existente como consecuencia de una mediación aristocrática (Federico Gana) y mesocrática (Mariano Latorre).

\section{Ciccarelli}

La obra de Alejandro Ciccarelli, Vista de Santiago desde Peñalolén, devela los discursos vinculados a la escena fundacional y a la construcción inaugural de un imaginario nacional. Gracias a la gestión del cónsul de Chile en Río de Janeiro, el pintor napolitano será contratado, en 1848 por el gobierno de Manuel Bulnes, como primer director de la Academia Nacional de Pintura. Se trata de un proyecto estatal que impulsa una producción pictórica nacional. En el caso de las letras, José Victorino Lastarria, en 1842, exhortaba en su famoso discurso de Incorporación a la Sociedad de Literatura de Santiago a la producción de una literatura propia. No obstante, Ciccarelli, apegado a los estrictos principios del estilo neoclásico, cultivó el género histórico, la pintura de temas mitológicos y el arte 
decorativo religioso. Esta postura motivó algunas críticas entre las cuales destaca la del teniente norteamericano Gillis (fundador del Observatorio Astronómico de Santiago), quien afirmaba "que a pesar de llevar la Academia tres años de existencia no ha tratado de enseñar la técnica del paisaje, estando la ciudad rodeada de una naturaleza de rara belleza" (cit. en Pereira 69). Como consecuencia, Ciccarelli evolucionará "hacia un tímido pseudo-romanticismo, sobre la base de su talento para captar la luz" (69), dando así lugar a la obra Vista de Santiago desde Peñalolén o Puesta de sol en Peñalolén. Según Eugenio Pereira Salas, esta obra es el origen de la escuela paisajística nacional liderada posteriormente por el romántico Antonio Smith:

La tela es un autorretrato con paisaje al fondo. El pintor sentado cómodamente frente a su caballete, vestido con el severo atuendo burocrático que remata en su sombrero de copa, tiene junto a sí, su caballo Rabón. Unos árboles agazapados, retorcidos troncos que emergen de un grupo de peñascos, complementan el primer plano. Al fondo, en alejamiento de lontananza, partida por los verdes cuarteles de las sementeras, se observa la línea sinuosa de la cordillera de la Costa. Buscando efectos lumínicos, a la manera de un cuadro dentro de otro cuadro, sobre la tela que trabaja el artista, se refleja la puesta del sol, en atinada composición (69-70).

Por otro lado, Ricardo Bindis destaca las lejanías, el cromatismo de ocres y rojizos y la amplia panorámica del lugar (51). También se advierte un “ajardinamiento” del valle a través de los planos agrícolas que el pintor traza con líneas rectas. Es decir, el entorno del segundo plano remite a un espacio ya intervenido por la técnica, mientras que el primer plano, donde el pintor se sitúa, representa un espacio silvestre. Cabe destacar que este primer plano natural no está repetido en la tela.

La obra representa dos veces (la de la pintura en sí y la de la pintura dentro de la pintura) el valle central al cual se ha accedido visualmente desde una perspectiva privilegiada: la altura precordillerana (Peñalolén). La insistencia en el Valle Central puede ser interpretada como un afán por representar a toda la nación a través de dicho paisaje. Ante la diversidad de paisajes existentes al interior del territorio nacional, el valle se presenta, según Alfredo Jocelyn-Holt, como un eje articulador que garantiza una única nación: "Son demasiados los paisajes; por tanto, a menos que aceptemos que son también muchos los posibles Chiles (postura que nadie ha pretendido sostener), es obvio que debe existir al menos un eje desde donde se articula lo que venimos denominando históricamente Chile, es decir, el Valle Central" (121). De ahí entonces que el historiador hable de "[l]a centralidad del Valle Central" (120), tautología que Ciccarrelli ya habría planteado a través de su puesta en abismo6.

El romanticismo de esta pintura está dado, en parte, por los efectos cromáticos de una luz crepuscular que recrean el paraje. En el paisaje de Ciccarelli, la oscuridad de la noche es inminente y permite la visión del pintor. Se trata de una experiencia en cierta medida semejante a la planteada por el poeta romántico alemán Novalis: “Pero me vuelvo

6 Para una definición de puesta en abismo, ver Dällenbach, Lucien. El relato especular. Madrid: Visor, 1991. 
hacia el valle, a la sacra, indecible, misteriosa Noche. Lejos yace el mundo [...]" (Himnos a la noche 65). La noche es entonces el recurso plástico que permite "romantizar el mundo. Así se recupera el sentido primitivo. Romantizar no es más que una potencialización cualitativa [...] Dándole a lo corriente un sentido superior, a lo vulgar un aspecto misterioso, a lo conocido la dignidad de lo desconocido, a lo finito una apariencia infinita, así es como [el poeta] lo romantizó todo" (Novalis, Fragmentos Escogidos 112).

Finalmente, este paisaje despliega en toda su magnitud las convenciones del género: espacios abiertos, miradas enmarcadas y ausencia humana que, en el caso de Ciccarelli, solo se relativiza con el autorretrato del artista. Tal representación de la figura humana sufre de cierta elipsis, ya que no vemos su rostro. En este sentido, no se trata de un autorretrato convencional, sino más bien de un sujeto que pierde su individualidad, aunque conserva su rol de artista como rasgo particular. La figura humana que nos da la espalda es entonces un pintor, sea o no el mismo Ciccarelli, configurado con rasgos burgueses: el sombrero, la chaqueta y el caballo. Se trata, en efecto, de un sujeto que ha dejado momentáneamente la ciudad para contemplarla desde cierta perspectiva. En efecto, si bien la ciudad de Santiago no tiene lugar en la pintura, sí es posible reconocer algunos elementos geográficos que la enmarcan: el cerro Santa Lucía, la cumbre del cerro San Cristóbal y la cordillera de la costa. Santiago, ciudad aludida en el título de la obra, se presenta más bien fantasmalmente por medio de tales huellas.

\section{Blest Gana}

Considerando el modelo de Bernardo Subercaseaux sobre las escenificaciones del tiempo colectivo, la novela de Alberto Blest Gana, Durante la reconquista, debería considerarse como expresión del tiempo de integración (1890-1920), ya que fue publicada en el año 1897, treinta y cinco años más tarde que la publicación de Martín Rivas (1862). Sin embargo, los límites de los periodos identificados tienden, algunas veces, a desdibujarse tal como el mismo autor lo admite: "Las escenificaciones aludidas se prolongan, sin embargo, más allá de las décadas de plena vigencia, llegando incluso a sobreponerse e interactuar, a veces polémicamente entre si” (Subercaseaux, Nación y Cultura 12). Dado lo anterior, es posible pensar la novela Durante la reconquista como parte de una escena fundacional o refundacional, puesto que apelaría a la recuperación de una unidad nacional tras la revolución de 1891:

Blest Gana debe evocar un Chile que se aleja en el recuerdo tras largos años vividos en París, un Chile que además se erige en un lugar de liderazgo en el contexto del continente, robustecido tras la Guerra del Pacífico, pero que también ha debido atravesar un momento de conflicto y división internos con la guerra civil del 91. Así, el mensaje de unidad nacional que portaría la novela se hace más visible en el marco de la coyuntura histórica en la que surge (Viu 235). 
Por otro lado, la participación de Durante la Reconquista en una escena fundacional, pese a su año de publicación, también se vislumbra en la relación de coherencia establecida por Pedro Lastra entre dicha novela, el artículo "De los trabajos literarios de Chile" (1942) y el discurso de incorporación a la Facultad de Humanidades de la Universidad de Chile (1961). En estas dos últimas composiciones, Blest Gana proclama los méritos de la novela histórica para la conformación de las letras nacionales:

Es oportuno acercar las ideas contenidas en el artículo de 1859 y en el Discurso de 1861 a sus novelas futuras, porque tal relación muestra la coherencia de su conducta intelectual. En efecto, Blest Gana definió con gran claridad las tareas del escritor de su tiempo y las asumió como una suerte de misión. Durante la Reconquista es una prueba admirable de esa conducta" (Lastra 262). De este modo, el relato de Blest Gana, al ser considerado una novela histórica, articula lo nacional, lo histórico y lo novelesco para configurar un solo orden: "Si Martín Rivas es la gran novela de costumbres del siglo XIX, Durante la Reconquista es la novela histórica fundamental de esos años (Viu 235).

Ahora bien, ¿cómo se lleva a cabo una articulación entre esta novela histórica y el paisaje? Las descripciones de la Cordillera de los Andes, las cuales abren y cierran la novela, funcionan como el telón de fondo de una escena social y como el espacio donde se llevará a cabo la hazaña independentista (las tropas de San Martín y O'Higgins bajan por las laderas cordilleranas para dar fin a la reconquista española). El narrador implícito en estas descripciones contempla la belleza del entorno desde una posición tal que su mirada abarca panorámicamente la misma cordillera y el valle del Mapocho. En estricto rigor, se trata de un narrador que debió situarse en la cordillera de la costa para ver lo que pudo ver y así componer el paisaje que efectivamente compuso:

Desde las cumbres nevadas de los Andes, el sol, como enamorado de la tierra, la abrazaba. Su tibia caricia, de fulgurante luz, había dorado con sus resplandores la falda de la cordillera, disipando con su aliento, como se borran al despertar los recuerdos de un sueño, los jirones flotantes de su velo de brumas matinales. Macul y Peñalolén, iluminados de súbito, enviaban a Santiago su sonrisa de verdura. Había besado con su saludo del alba la despoblada cima del cerro San Cristóbal y partido sus rayos sobre los riscos del Santa Lucía. Había corrido después, a lo largo de la pedregosa caja del Mapocho, tiñendo de rubio color las turbias ondas del río, y descendiendo poco a poco en raudales de claridad, de los tejados a las calles. Penetrando por patios, por huertos y por jardines, despertaba la vida y el movimiento, tras su paso vencedor (Blest Gana 29).

La visión paisajística del narrador es romántica y moderna. Al destacar el cromatismo del espacio como efecto del amanecer, nos permite apreciar cómo la luz del sol ha generado el nacimiento de un espacio, el Valle Central, donde se llevará a cabo un cambio de orden, una sustitución revolucionaria de autoridades y ejes que modificarán la experiencia del sujeto. Así, la Cordillera de los Andes será el fiel y permanente testigo de los cambios venideros. La tradición ha sido adjudicada a un paisaje supuestamente 
inamovible, mientras que la modernidad será aupada por la acción política de los héroes nacionales y de los enamorados que la novela recrea a través de sus historias de amor. Al mismo tiempo, la Cordillera de los Andes establece un contrapunto con el huerto, paisaje más bien destinado a escenas íntimas o amorosas o a ser reflejo de estados anímicos y emocionales del sujeto que lo contempla. Así, mientras la Cordillera se la representa en toda su magnitud y grandeza, el huerto será destacado como un hortus conclusus, un espacio cercado y cerrado que, a diferencia de la cordillera, es testigo de episodios íntimos, los cuales, sin embargo, también tendrán implicancias políticas y públicas. Es el caso, por ejemplo, de los paseos de Trinidad Malsira por el huerto descuidado de sus padres, donde "[c]ada árbol era ahí un amigo de su infancia" (485).

Si Cicarrelli representa el paisaje del atardecer, Blest Gana, en la extensa cita ya presentada, lo hace durante el amanecer, permitiendo una posterior presentación del sujeto popular colectivo. Tanto el prólogo escrito por Juan Durán Luzio e Iván Jaksic a la edición crítica de la novela (2010) como la reseña de Antonia Viu, recalcan la presencia del pueblo en la novela:

Mucho se ha dicho sobre el relieve que el pueblo adquiere en Durante la reconquista en relación con otras obras de Blest Gana. El prólogo destaca el hecho de que la novela comience y termine con "sendas escenas de masas en movimiento" (17), pero junto con la glorificación del poder que esa masa alcanza, es inevitable advertir la imagen de una fuerza ciega, sin un propósito, como la de un rebaño de animales que puede huir en estampida en cualquier momento (Viu 236).

Esta muchedumbre terminará siendo liderada por una nueva autoridad encarnada en Manuel Rodríguez. La sustitución de autoridad, si consideramos los dos extremos de la novela, es tremendamente significativo: al comienzo, durante la descripción de la procesión, el pueblo atiende a la autoridad eclesiástica quien interpreta el triunfo de la reconquista de la corona española como intervención de los cielos, mientras que, al final de la novela, la muchedumbre es "civilizada" por héroes aguerridos y secularizados. Es preciso indicar, no obstante, que el sujeto popular no es representado en el paisaje propiamente tal. En efecto, el paisaje cordillerano es más bien el testigo de los hechos públicos y políticos vinculados al origen de un país independiente y no el escenario de la muchedumbre propiamente tal. Solo los héroes tienen lugar en el paisaje.

En suma, el paisaje en Blest Gana supone una presentación del pueblo más bien relativa y parcial. Las descripciones altamente estilizadas del entorno corresponden a la cordillera andina o al campo, pero no al valle del Mapocho, lugar en el que se lleva a cabo parte de la acción histórica y novelesca. El narrador instalará un contraste entre su mirada y la de uno de los personajes. Si la del primero construye un paisaje vacío de presencia humana, la del segundo da lugar a un cuadro de costumbres y un paisaje:

Con más de una hora delante de sí, don Jaime no se atrevió, sin embargo, a volver a la tertulia de la tienda. Prefirió ir al tajamar, donde su meditación seguía el turbio curso de las aguas del Mapocho. Hacia el Oriente, tras el árido cerro San Cristóbal, se empecinaban buscando el cielo las blancas crestas de los Andes, 
con la majestad inconmovible de lo eterno. El río, sobre su lecho pedregoso, murmurando, juntaba con trabajo sus aguas al llegar al puente Cal y Canto, para no pasar bajo sus grandes arcos como una pobre acequia de arrabal. Al poniente, la planicie, vaga y despoblada entonces, tenía hacia el horizonte reflejos de mar lejano, como el principio del espacio infinito. Don Jaime no se dio cuenta de la grandeza del paisaje que tenía a la vista. En la caja del río, dos hombres, que llenaban con arenas las árguenas de una tropa de cuatro o cinco borricos, mientras que éstos luchaban, tan ilusos como pacientes, por descubrir algunas hebras de verdura entre las piedras, le inspiraron pensamientos filosóficos. La envidia secreta del poderoso, que supone a los rústicos un alma exenta de cuidados, le hacía compararse a los burreros. "Estos rotos irán a comer sin cuitas una tortilla y un pedazo de chancho arrollado, mientras que él con su sangre azul de noble y su riqueza, sacudido y estropeado por las agitaciones de la existencia, como una puerta entreabierta que el viento azota continuamente contra el marco, no podía distrae el pensamiento de la "cara que le pondría don Mariano" (Blest Gana 569).

El narrador y el personaje tienen diferentes objetos de miradas y sensibilidades. Mientras el primero sí es capaz de contemplar la belleza del paraje y, por lo tanto, de construir un paisaje, el personaje, don Jaime, detiene su atención en quienes trabajan en el lecho del río Mapocho, dando la espalda a la vista de los cerros: "Don Jaime no se dio cuenta de la grandeza del paisaje que tenía a la vista" (569).

Es posible concluir que el paisaje de Blest Gana corresponde a una mirada de elite: al sujeto popular se le representa como parte de una masa sedienta de una nueva autoridad para su contención, mientras la cordillera deviene en el escenario magnífico de un proyecto político y cultural liderado por un pensamiento ilustrado y liberal. En efecto, "[I] gran literatura latinoamericana del siglo XIX es de índole marcadamente burguesa" (IX), nos recuerda Jaime Concha en su prólogo a Martín Rivas mientras que, en términos de Bernardo Subercaseaux, el paisaje no sería más que un agente civilizador.

\section{Federico Gana}

Los paisajes vislumbrados en Días de campo son fácilmente identificables para un lector chileno: se trata de campos agrícolamente intervenidos que, bajo la mirada del cordón andino, se despliegan a lo largo del valle central. El lector reconoce el espacio narrativo como el Valle Central de Chile solo a través de referentes "de toda la vida" presentes en el lugar: el álamo, la zarzamora que trepa por el muro de adobe que va por el costado del camino "a medio morir saltando", los cercos de ramas, los patios y jardines un tanto descuidados son el testimonio del pulular doméstico. Esta particular figuración del espacio como paisaje familiar explica también el escaso uso de topónimos. El lector no los necesita para identificar el Valle Central. De esta manera, tan solo se nombra la Cordillera de los Andes y, en menor medida, la Cordillera de la Costa. El "Norte" solo figura como un extremo lejano 
del país y se alude a la ciudad de Santiago como un referente un tanto más próximo. Lo mismo sucede con la determinación cronológica. El único dato histórico presentado es una ya lejana Guerra del Pacífico. Es como si los relatos padecieran de una especie de indeterminación que abstrae a los espacios del devenir histórico y los convierte en paisajes situados, aparentemente, más allá de ese mismo devenir. En lugar del tiempo histórico, solo tenemos la sucesión de las estaciones y sus efectos que van pintando el paisaje: la lluvia, las hojas amarillas, el calor.

No obstante, la mediación subjetiva que todo paisaje supone no está invisibilizada. Los cuentos presentan un narrador muy personalizado. Por ende, el sujeto que observa e interpreta el espacio está altamente determinado: se trata del dueño de las tierras que, por lo general, observa el paisaje estando montado a caballo. El cuento "La señora" comienza haciendo alusión al caballo del narrador: "Hacía ya tres horas que galopaba sin descansar, seguido de mi mozo, por aquel camino que se me hacía interminable. El polvo, un sol de tres de la tarde en todo el rigor de enero, el mismo sudor que inundaba a mi fatigado caballo, me producían un ansia devoradora de llegar, de llegar pronto" (Gana 5) Lo mismo sucede en el cuento titulado "La Maiga": "Mandé ensillar mi caballo y un instante después salía. El caballo se estremecía de frío y de impaciencia bajo el corredor. Subí rápidamente y partí al galope" (16). El comienzo del cuento "Crepúsculo" también posiciona al patrón que narra los cuentos en la actividad ecuestre:

Regresaba de cazar, una fría tarde de invierno, y marchaba al lento paso de mi caballo al lado de la línea férrea, por un camino vecinal bordeado de sauces llorones. A mis espaldas dejaba las azules montaña de la costa, donde el sol acababa de ocultarse, y a mi frente se extendía el caserío del vecino pueblo de L.; más allá divisaba el panorama de la cordillera de los Andes, que se destacan de sombrías brumas, entre largos y caprichosos filos de las pardas alamedas de los potreros y los caminos lejanos (44).

De la cita anterior, destaca también la variación verbal respecto al tiempo: todas las acciones ejecutadas por el narrador acaecieron en un tiempo pasado, ("regresaba", "marchaba", "dejaba”), mientras que los Andes "destacan" en un eterno presente sobre una bruma que, por su misma naturaleza, es fugaz y transitoria. La contradicción de esta descripción (los Andes no pueden destacar perpetuamente sobre un fenómeno pasajero) indica el afán del ojo paisajístico de ver el espacio como una permanencia inamovible.

Los efectos en el paisaje del constante movimiento del observador quien, no lo olvidemos, anda sobre un medio de transporte, son la variación de los planos más inmediatos y la extensión de estos mismos a medida que la línea de horizonte se desplaza por el avance del jinete: "A medida que avanzaba, el paisaje principiaba a variar. Añosos álamos y sauces daban sombra al camino; divisaba verdura, chácaras, pastales de trébol, animales vacunos, aguas corrientes... De cuando en cuando, tras la alameda, asomaban algunos humeantes ranchos de inquilinos" (6). Los efectos de variación en el paisaje contrastan con la permanencia absoluta de los Andes divinizados como si estos tuviesen del don de la ubicuidad, independientemente de donde se encuentre el narrador/observador: "A lo 
lejos, la enorme mole violácea de los Andes, despojada de sus nieves, emergía con violenta claridad sobre un cielo sin nubes, pálido y brillante" (5).

En los cuentos de Federico Gana, la inclusión del sujeto popular campesino puede ser observada desde la categoría estética de lo pintoresco. Según J. Maderuelo, en el contexto del empirismo inglés, William Gilpin (1724-1804) desarrolló la categoría de lo pintoresco al oponerla a las categorías de lo bello y de lo sublime:

Como categoría, lo pintoresco permite contemplar y valorar estéticamente aquellas cualidades que no entraban dentro de las categorías de lo bello y lo sublime, establecidas por Burke, tales como lo rugoso, lo áspero, lo deforme, lo irregular, lo variado, lo tosco... cualidades todas ellas que producen placer sin estar mesuradamente proporcionadas ni provocar patetismo, es decir, sin llegar a ser bellas ni sublimes (Maderuelo, "La teoría de lo pintoresco..." 33).

En dicho contexto cultural, el jardín se reveló contra las jerarquías del jardín barroco, el cual se había formalizado al responder estrictamente a los ejes impuestos por palacios y edificios. Es así como nace la noción de "jardín paisajista”, espacio en el cual se reproducirá la naturaleza auténtica como símbolo de libertad en oposición a la naturaleza enajenada de Le Notre. Ahora bien, este jardín liberado del rigor arquitectónico "presentará escenas como si fueran cuadros" (18). En efecto, "[l]a pintura... había servido para enseñar a contemplar las bellezas que se hallan en los escenarios que ofrece la naturaleza; de esta manera se empezó buscando en los campos aquellos efectos plásticos y luminosos que previamente se habían admirado en los cuadros" (19). El término "jardín pintoresco" surge entonces cuando el jardín, en una composición que disimula su carácter artificial, se iguala a la pintura.

Mirar el espacio rural como si fuese un cuadro. El paisaje se construye cuando la mirada convierte el entorno en pintura. En Federico Gana, esta mirada pintoresca se manifiesta en la presentación de construcciones arquitectónicas y de figuras humanas:

tenía ante mí una reja de madera pintada de blanco, a través de la cual se divisaba una huerta de hortalizas y un edificio con esa arquitectura sencilla y primitiva, peculiar en nuestras antiguas construcciones campesinas: enorme techo de tejas, bajas murallas, anchos y sombríos corredores (Gana 6-7).

Dado su estado ruinoso, lo pintoresco también puede ser advertido en el cementerio descrito en el cuento "La Maiga": "Por encima de las tapias ruinosas, entre viejos sauces y rosales, asomaban algunos mausoleos: enormes columnas truncadas, teñidas de cal, ángeles de yeso, grandes cruces negras con adornos de papel blanco. iPobres muestras de la vanidad lugareña" (17).

En Días de campo, la figuración humana también es pintoresca. En su ensayo titulado "Sobre el viaje pintoresco", Gilpin establece que la figura humana presente en el paisaje puede ser digna de atención, bajo ciertas condiciones, para el ojo pintoresco:

No se pretende el estudio anatómico de las figuras, las miramos únicamente como ornamento de las escenas. En las figuras humanas, no contemplamos tampoco la exactitud de la forma ni la expresión más allá de lo que se muestra en acción; 
consideramos solamente las formas generales, los ropajes, las agrupaciones y las ocupaciones. Las encontraremos a menudo casualmente, con mayor variedad y belleza que las que podría proporcionarnos la mejor selección (87).

Es decir, la figura humana en el paisaje solo es ornamental y accidental. Su descripción jamás será detallada y se le representará en acción. La figura del campesino descrita por Gana tiene características similares a las expuestas por Gilpin. En el cuento "La señora", el narrador llega a una casa de campo en cuyo patio, al fondo, puede divisar la figura de Daniel, un hombre de modestos orígenes. A medida que el narrador avanza por el patio, Daniel permanece parado junto a un caballo ensillado, arreglando, al parecer, una brida:

Quien así me respondía era un individuo alto, obeso, poderosamente constituido. Representaba de cuarenta y cinco a cincuenta años, y vestía el traje común a nuestros mayordomos de haciendas: pequeña manta listada, chaqueta corta, pantalones bombachos de diablo fuerte, enormes espuelas y sombrero de paja de anchas alas. Su rostro cobrizo, de facciones gruesas y duras, singularizábase por el estrabismo y la inmovilidad de una de sus negras pupilas, que parecía cristalizada, mientras la otra tenía un brillo y una vivacidad extraña (Gana 7-8).

Se trata de una visión casual por parte del narrador quien destaca la ocupación y los ropajes de la figura humana, situándola como parte de una escena que no es otra cosa que la ramada, el patio y el camino de acceso.

En suma, Días de campo ofrece una serie de "postales” del Valle Central a través de las cuales la nación es identificada. Su reformulación integra pintorescamente a un sujeto popular, campesino y mestizo. Dicha representación supone una apropiación aristocrática de lo popular: el sujeto de elite incluye al sujeto popular en el orden bajo una representación y estética particular. Lo pintoresco es entonces la mirada que representa al campesino para matizar su otredad y así integrarlo a una comunidad mesuradamente ampliada.

La figuración popular pintoresca en la obra de Federico Gana guarda cierto diálogo con la pintura titulada La poda (ver Figura 2) de Celia Castro (1860-1930), una de las alumnas más aventajadas de Pedro Lira y la primera mujer chilena dedicada profesionalmente a la pintura.

En esta obra, las figuras humanas no destacan por su fisonomía, sino más bien por los movimientos de la faena que realizan y que da título a la pintura. Sus rostros están escondidos por los mismos cuerpos en trabajo: el brazo del hombre se superpone a su cara y el hombro inclinado de la mujer nos impide nuevamente reconocer sus facciones. Junto a ello, la distancia de la observadora impide una proximidad a la figura humana y así el género del paisaje desplaza todo posible retrato. ¿Por qué es un paisaje cuando el espacio rural aparece mediatizado por la faena agrícola? Se trata de una naturaleza altamente intervenida: los árboles frutales son drásticamente podados y el huerto es como si estuviese doblemente cercado tanto por el muro de adobe del segundo plano como por aquel que señala el perfil de una de las aguas de un techo de lo que fue tal vez, por su altura, una bodega o una casa patronal. Si la naturaleza está intervenida, aquí el trabajo está algo idealizado sobre todo en el caso del hombre; es como si este se alzara al cielo 
y lograra una cercanía con la luz diurna que la mujer, apegada a la superficie de la tierra, no puede gozar. El hombre practica una danza sobre el árbol, es decir, entre la tierra y los cielos. La mujer, en cambio, recoge los despojos de esa poda-danza al amontonar las ramas. El contraste de luz y sombra es paralelo a una oposición de género entendido como la construcción de la diferencia sexual. Se trataría, tal vez, de una división sexual del trabajo en caso de una aproximación social a esta pintura. No obstante, el movimiento supuesto en los cuerpos recuerda el modo a través del cual Gilpin describe pintorescamente la figura humana inserta en el paisaje. Lo pintoresco ha sido entonces un modo de mirar de Celia Castro para integrar al sujeto popular en un paisaje familiarmente nacional.

\section{Zurzulita de Mariano Latorre: el campesino y la barbarie}

Zurzulita es la novela de la tierra por excelencia en el panorama de las letras chilenas. Según Juan Gabriel Araya, Mariano Latorre fue el principal representante del criollismo, movimiento que "propiciaba una literatura centrada en la tierra, a fin de entregar las particularidades propias del país a través de la representación del hombre y del paisaje rural” (49). Según la sensibilidad regionalista, las particularidades propias de la nación se encuentran, más que en la ciudad, en el campo y sus habitantes. Para dar cuenta de tal realidad, Mariano Latorre, recogiendo las convenciones de época, pretende una mirada documentada y objetiva sobre el espacio. Por lo tanto, el paisaje se construye desde una supuesta impersonalidad:

Resulta pertinente recordar que la producción de los relatos regionalistas -o mundonovistas en la terminología de Francisco Contreras (1877-1933)- se realiza en las primeras décadas del siglo $\mathrm{xx}$ bajo la influencia del naturalismo y del positivismo europeo. De acuerdo con el canon naturalista la representación de la realidad externa debía ser realizada con el máximo de objetividad. Es por eso que nuestro autor, dirigiendo su mirada hacia el ámbito agrario, recurría a un procedimiento documental para reafirmar el carácter impersonal del relato, como lo prueba la incorporación de voces dialectales que requerían de un glosario para su comprensión cabal (Araya 50).

La objetividad se materializa en la escritura de Mariano Latorre al ofrecer un conocimiento que simula la exactitud científica. En efecto, el narrador nombra, señala y describe una serie de especies de la flora y fauna endémica, así como entrega datos sobre la geografía del sector sujetos a un estricto sentido de veracidad.

Pese a lo anterior, el paisaje de Mariano Latorre es complejo, ya que muchas veces estará mediado por la sensibilidad del protagonista, Mateo Elorduy. Una vez que su padre muere, decide abandonar el pueblo de Loncomilla e incursionar en el negocio agrícola, instalándose consecuentemente en Millavoro, un fundo ubicado en las colinas de la Cordillera de la Costa. Ante la presencia amenazante y perjudicial del antiguo administrador, don Carmen Lobos, la mirada paisajística de Mateo oscila entre una idealización del campo 


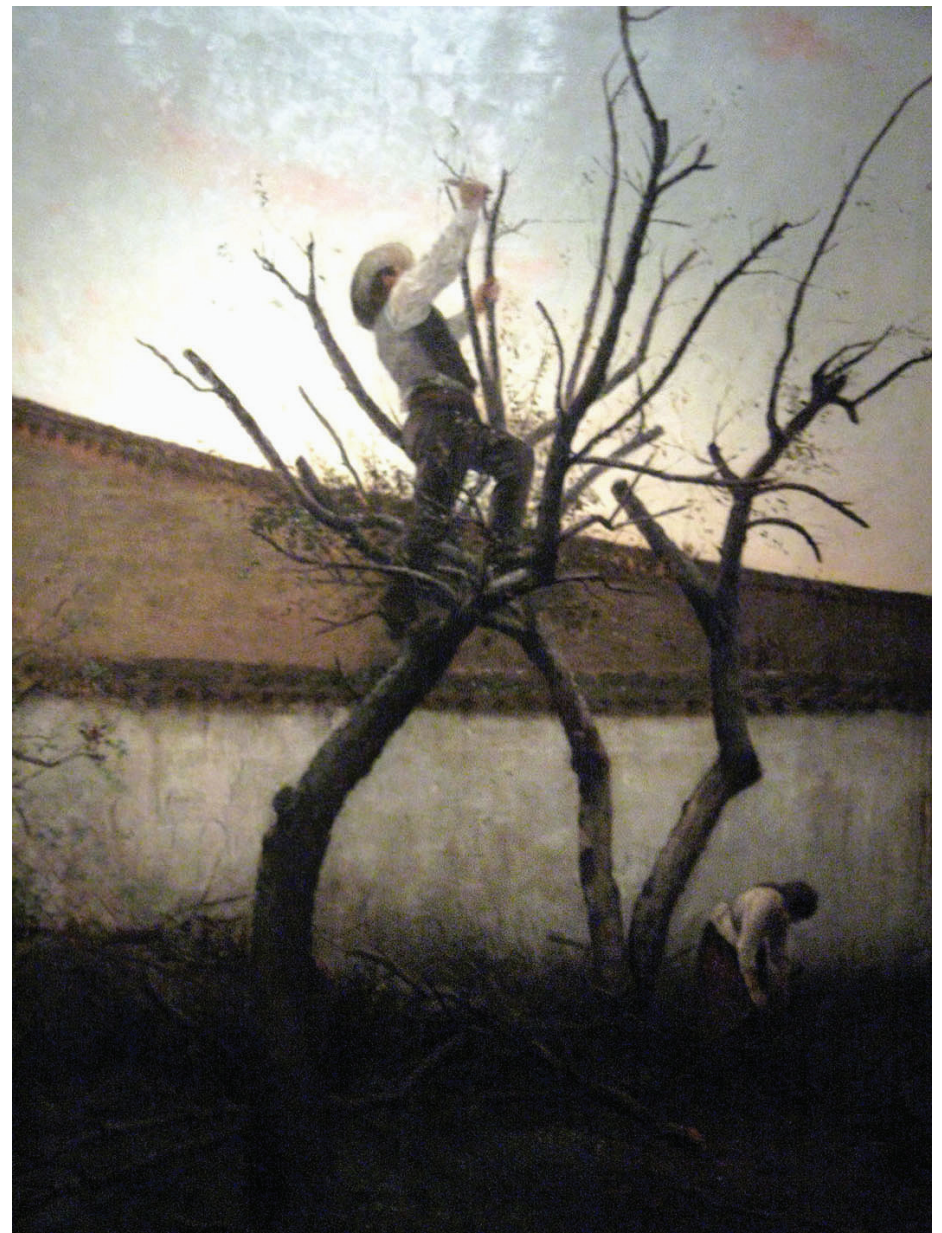

Figura 2. Celia Castro. La poda. Fuente: Pinacoteca Universidad de Concepción. Sitio web.

como fuente de belleza arcádica y vigorizante y, por el contrario, como una degradación del paraíso, es decir, una desconocida y peligrosa experiencia laboral conducente a una catástrofe inminente. En la imagen paradisíaca del paisaje, el trabajo agrícola es visto como parte de una pacífica comunidad en que las diferencias sociales se suavizan por el afecto, como una aventura, un sueño en el que el sacrificio y las penurias del campesino no figuran: Ya sentíase un campesino. Confusamente, movíanse teorías audaces en su cerebro...iQué hermoso sería vivir entre árboles, en aquel rinconcillo montañoso que su imaginación creaba como un pequeño paraíso chileno. Querría a sus inquilinos, a esos pobres hombres sin aspiraciones, resignados ante el patrón como bestias domésticas y sonreíase al pensar, si entre aquellos servidores suyos de Millavoro habría una muchacha hermosa y fuerte con la cual tejer un idilio, junto a las parvas doradas o entre los pámpanos de la viña (Latorre 23-4). 
Llama la atención la alusión a un "paraíso chileno". Al parecer, el texto desenmascara la ideología que asocia e identifica a la nación con un Edén, señalando su falsedad y la equivocación de la conciencia que perpetúa dicha construcción. En un afán que revisa críticamente los discursos fundacionales del siglo XIX, el criollismo, el cual ha integrado por medio de la representación nuevos niveles sociales, nos recuerda que la nación no es un paraíso, sino más bien un territorio donde la barbarie y la civilización entran en conflicto?.

La idealización del paisaje como paraíso que elabora la conciencia del protagonista supone una mirada ingenua, resultado de un vida en la que el esfuerzo no ha sido necesario para sobrevivir, una mirada que la novela vincula, significativamente, con la del poeta: "lluso como un poeta, la facilidad de la vida, el no haberse preocupado nunca de ganarla, le habían hecho ver sólo el lado amable de las cosas, el aspecto risueño. En su fantasear ingenuo, el porvenir, era, como el sueño de Jacob, una escala que conducía al cielo, toda palpitante de sedosas alas angélicas, donde las contrariedades no asomaban sus ásperas greñas de demonios" (25). Al mismo tiempo, esta mirada será complementada con la del narrador, quien, si bien observa el entorno resaltando su belleza y accediendo a la contemplación placentera, no duda otra veces en señalar la pobreza y precariedad del erosionado entorno rural: "Ranchos sucios, pobrísimos, tierras quebradas, llenas de matorrales y de zarzas... Por ningún lado veíanse pastizales ni vacunos [...]” (65).

La mirada paisajística del personaje protagonista que a veces se superpone a la del narrador se visualiza también con la representación de objetos percibidos auditivamente como lo es el canto de los pájaros: “Fresco, alegre, descansado, Mateo escuchó en su cama el canto de las diucas madrugadoras, cuyos aleteos rápidos, su suave runruneo, parecían agitar el aire de la pieza. Corrió la cortinilla modesta de la ventana que daba al campo y durante largo rato sintió la respiración del alba que se espaciaba sobre la montaña adormilada" (45). Cabe destacar la figuración de la ventana, encuadre o marco de la mirada tradicionalmente vinculado al paisaje que indica el lugar de observación (el interior de una casa o construcción) y el objeto a convertirse en paisaje, es decir, el espacio exterior:

El paso decisivo, sin embargo, es la aparición de la ventana, esta vedutta interior del cuadro que lo abre al exterior. Este hallazgo flamenco representa ni más ni menos que la invención del paisaje occidental. La ventana es, efectivamente, el marco que, al aislar al país en el cuadro, lo convierte en paisaje. En este sentido, es muy probable que la primera significación de la palabra "paisaje" -landschap, literalmente, 'trozo de país' en neerlandés-, aparecida en la segunda mitad del siglo $\mathrm{XV}$, designara esta porción de espacio delimitada por la ventana pictórica (Roger 71).

7 Al estudiar el paisaje criollista en su vinculación ideológica con la nación, la importancia que adquiere la naturaleza es crucial, ya que supone una revisión crítica del proyecto de modernización del siglo xIX. Para Leonidas Morales, “... la opción por la naturaleza de criollistas y regionalistas era en el fondo la opción por un condenado a muerte. Despojada de las funciones culturales que tuvo dentro de la sociedad tradicional, que eran también funciones de poder, la naturaleza cae en el dominio de lo bruto, de lo caótico e irracional" (17-8). Lo anterior se explica, según el autor citado, a través del auge que tuvo la ciudad en el desarrollo del capitalismo, marginando así la naturaleza en tanto fundamento de la sociedad precedente. 
Si bien la mediación del protagonista es indesmentible, la objetiva y documentada voz del narrador es decidora en cuanto a la presentación misma del paisaje. En efecto, la oscilante aproximación emocional de Mateo acusa un paisaje que no logra configurarse plenamente en el texto. El sujeto acusa solo una huella del paisaje que ya se ha ausentado o velado. Es el narrador, por el contrario, quien toma el pincel y corre la cortina para señalarnos un contorno que se ha vuelto paisaje gracias a la regulación de la nítida luz invernal:

La clara mañana de agosto era de una limpieza aurea, una de esas mañanas de sol primaveral en un paisaje de invierno. Los álamos del camino, apenas salió del pueblo, erguíanse como rígidos plumeros grises en cuyo varillaje temblequeaban aún hojuelas amarillas con aleteos de pajarillos. En el esqueleto de un acacio rojeaban las bayas abiertas, sin semilla, como hociquitos que se asfixian. La limpieza y profunda quietud azul del cielo de agosto abrazaba en su claridad la mancha morena del paisaje (Latorre 23).

El conocimiento documentado del narrador sobre el territorio disfraza el paisaje, volviéndolo pura presencia. Es como si sobre el carácter mimético del paisaje superpusiera una presentación de la esencia misma del entorno. En suma, lo que lleva a cabo es un enmascaramiento de la representación para que esta aparezca como presentación.

Cabría preguntarse cuáles son los espacios nacionales y cuáles no para el crioIlismo en general y para Mariano Latorre en particular. El autor, quien ha hecho del la escritura un oficio y una profesión, explora el campo desde su origen urbano y experiencia como funcionario, ya que en el espacio rural se encontraría la "verdadera" esencia de la identidad chilena: "El resultado de este trabajo de campo, la síntesis de sus observaciones, será la búsqueda en el espacio rural de la identidad nacional profunda” (Álvarez 42-3). En este sentido, el espacio urbano es más bien el escenario de la impostación que entorpece el hallazgo de lo verdaderamente chileno. Mariano Latorre deja ver un desconocimiento o una indiferencia ante lo que realmente ocurría con la población al interior del territorio nacional: "Paradójicamente, sin embargo, esta voluntad tiene cada vez menos que ver con lo que verdaderamente ocurre en el campo chileno, porque desde principios de siglo las tasas de crecimiento de la población rural disminuyen mientras las urbanas aumentan" (43).

Esta negación mimética de lo urbano guarda también un distanciamiento con Blest Gana. En efecto, en la novela fundacional Martín Rivas, Santiago tiene una importancia capital negada posteriormente por Mariano Latorre. Si el autor del siglo XIX "promueve la reconciliación económica, política y moral de la sociedad" (41), Mariano Latorre, por el contrario, revisa críticamente tal comunidad imaginada por los discursos fundacionales para narrar el quiebre trágico de tal armonía. En este sentido, el autor de Zurzulita está repensando los espacios nacionales para luego (re)presentar nuevos espacios. En efecto, niega la ciudad como el referente que promete el hallazgo de una identidad nacional ya dada y como el escenario de una reconciliación comunitaria, ya que en tal imaginario nacional se ha excluido, entre otros, al campesino. En segundo lugar, dirige su mirada al campo, entorno extremadamente agreste que determina al sujeto, transformándolo en una figura 
de amenazante barbarie: don Carmen Lobos, quien asesinará al que, infructuosamente, pretende promover el orden, la honradez y el progreso en el campo. Al mismo tiempo, el campo traiciona la promesa de amor hecha a los héroes: la novela carece de final feliz; los enamorados no logran proyectar su amor dada la muerte catastrófica del protagonista. En suma, el campo, si bien sintetiza una identidad nacional, no es capaz de configurar una utopía frente a la cual se construya un promisorio imaginario nacional. Así, el "nacionalismo" estético, rural y antiurbano" (41-2) de Latorre, para utilizar las palabras de Álvarez, radica justamente en el paisaje, es decir, en aquellas detalladas descripciones en las que el entorno rural "deshabitado" prevalece por sobre las presencias y acciones humanas. En otras palabras, el paisaje y la escala de valores implícita en él son la imagen de nación que el autor ofrece para que una comunidad de lectores se identifique con y en ella y es en tal proceso de identificación donde se llevaría a cabo la construcción de un sujeto nacional. El paisaje es entonces nuestra comunidad y a ese paisaje estamos llamados todos para conocerlo y vivirlo, para habitarlo y transformarlo en nuestro ethos nacional.

Esta chilenidad, esa "alma nacional" que promete un feliz día, se presenta sintéticamente en una imagen: el canto de la diuca, ave endémica de Chile. A través de una prosa más bien parecida a una oda tal vez un tanto relamida, la novela exalta la naturaleza endémica como el valor capaz de generar una nueva identificación nacional:

iDiuquita matutina, color de amanecer, qué grata es la chilladiza de tus trinos, diminutos como las semillas de que te alimentas! iEn tus alitas parece que el alba se hubiera depositado como un polvo invisible, el alba gris, el alba azul, donde aun palpita el centelleo de las estrellas! Y luego evocas el campo, las pataguas, el esterillo húmedo, la yerbita bravía que abre en cualquier rincón su florecilla anónima, la cabezuela aguda del zorro trasnochador en las cercanías del gallinero. iEres la voz del alba chilena, la reina de esa hora misteriosa que empieza con una leve mancha blanquecina y concluye con un inmenso hálito de oro! (Latorre 43; el énfasis es nuestro).

El canto del pájaro es entonces el alba, un renacer del alma del país.

\section{Conclusiones}

Para terminar, unas pocas ideas generales y conclusivas. La primera guarda relación con el carácter estético del paisaje y los recursos narrativos. Acostumbrados más a ver paisajes que a leerlos, los lectores podemos advertir, sin embargo, como el modo narrativo determina la forma del paisaje. Desde el grado de omnisciencia del narrador hasta su perspectiva y distancia, la narración construye un paisaje cuando la palabra se refiere a un espacio exterior bajo determinadas maneras.

La segunda conclusión hace referencia al carácter performático del paisaje: “El paisaje es, quizá, el único concepto moderno capaz de referirse a algo y, a la vez, a la descripción de ese mismo algo. El término remite tanto a una porción del territorio como 
a su imagen, a su representación artística y, también 'científica”' (Minca 209). De este modo, el entorno geográfico in situ puede ser también un paisaje, porque nuestra mirada describe el espacio real, recreándolo y volviéndolo paisaje. O sea, al describir paisajísticamente, no solo represento un referente previamente existente, sino que también lo produzco. Realidad y representación son entonces, en el caso del paisaje, entidades casi simultáneas y es en dicha contemporaneidad donde se rompen las jerarquías de la mimesis. El paisaje nombra y crea el mundo. En este sentido, el lector de los relatos y pinturas estudiados ve el entorno natural como dichas obras lo vieron. Como lectores, reproducimos con nuestra mirada sobre el entorno real el paisaje ya registrado en la contemplación artística. El paisaje nos enseña a ver la realidad y ese ver no es otra cosa que crear y proyectar nuestro espacio real.

Lo anterior devela la última conclusión la cual acusa el problema discursivo de la nación y su constitución ideológica. La naturalización del paisaje como mecanismo de identificación nacional se produciría a través de la mediación invisibilizada de las artes. Como un velo semitransparente, las obras estudiadas han obstaculizado la mirada, en términos de Victor Stoichita ${ }^{8}$, entre nosotros y el territorio nacional, olvidando así que nos enfrentamos más bien a apariencias muchas veces encantadoras.

\section{Referencias}

Álvarez, Ignacio. Novela y nación en el siglo xx chileno. Ficción literaria e identidad. Santiago: Ediciones Universidad Alberto Hurtado, 2009. Medio impreso.

Araya Grandón, Juan Gabriel. “Novela de la tierra: consideraciones ecocríticas sobre Zurzulita de Mariano Latorre”. Anales de Literatura Chilena 15 (2011). 49-60. Medio impreso. Berque, Agustín. El pensamiento paisajero. Madrid: Bibloteca Nueva, 2009. Medio impreso. Bindis, Ricardo. Pintura chilena Doscientos años. Santiago: Origo, 2006. Medio impreso. Blest Gana, Alberto. Durante la reconquista: novela histórica. Ed. Iván Jaksic y Juan Durán Luzio. Santiago: Universitaria, 2009. Medio impreso.

Concha, Jaime. "Prólogo". Martín Rivas. Venezuela: Biblioteca Ayacucho, 1977. Medio impreso. Gana, Federico. La señora. Santiago: LOM, 1998. Medio impreso.

Gilpin, William. 3 ensayos sobre la belleza pintoresca. Madrid: Abada, 2004. Medio impreso. Jocelyn-Holt, Alfredo. Historia General de Chile. 3. Amos, Señores y Patricios. Santiago: Sudamericana, 2004. Medio impreso.

Lastra, Pedro. “Alberto Blest Gana. Durante la reconquista. Reseña”. Revista Alpha 28 (2009): 260-263. Medio impreso.

Latorre, Mariano. Zurzulita. Santiago: Nascimiento, 1952. Medio impreso.

Maderuelo, Javier. “La definición de paisaje”. El paisaje. Génesis de un concepto. Madrid: Abada, 2005. Medio impreso.

8 Ver Stoichita, Victor. Ver y no ver. La tematización de la mirada en la pintura impresionista. Madrid: Siruela, 2005. 
---. "La teoría de lo pintoresco y la obra de William Gilpin". 3 ensayos sobre la belleza pintoresca. Por William Gilpin. Madrid: Abada, 2004. Medio impreso.

Minca, Claudio. "El sujeto, el paisaje y el juego posmoderno". El paisaje en la cultura contemporánea. Ed. Joan Nogué. Madrid: Biblioteca Nueva, 2008. Medio impreso.

Morales, Leonidas. “Introducción”. De muertos y sobrevivientes. Narración chilena moderna. Santiago: Cuarto Propio, 2008. Medio impreso.

Novalis. Himnos a la noche. Madrid: Cátedra, 1998. Medio impreso.

---. "Sobre el poeta y la poesía". Fragmentos. Escritos Escogidos. Madrid: Visor, 1984. Medio impreso.

Pereira Salas, Eugenio. Estudio sobre la historia del arte en Chile republicano. Santiago: Ediciones de la Universidad de Chile, 1992. Medio impreso.

Roger, Alain. "Vida y muerte de los paisajes. Valores estéticos, valores ecológicos”. El paisaje en la cultura contemporánea. Ed. Joan Nogué. Madrid: Biblioteca Nueva, 2008.

Sarlo, Beatriz. "Prólogo a la edición en español”. El campo y la ciudad. Por Raymond Williams. Buenos Aires: Paidós, 2001. Medio impreso.

Serraller, Calvo. "Concepto e historia de la pintura del paisaje" Los paisajes del Prado. Madrid: Nerea, 1993. Medio impreso.

Subercaseaux, Bernardo. “Literatura, Nación y Nacionalismo”. Revista Chilena de Literatura 70 (2007): 5-37. Medio impreso.

---. Nación y Cultura en América Latina. Diversidad cultural y globalización. Santiago: Lom, 2002.

Viu, Antonia. "Reseña de Durante la Reconquista”. Anales de Literatura Chilena 15 (2011): 235-247.Medio impreso.

Williams, Raymond. El campo y la ciudad. Trad. Alcira Bixio. Buenos Aires: Paidós, 2001. Medio impreso.

Recibido: 12 septiembre 2012

Aceptado: 11 marzo 2013 